\section{Elementary School Students' Needs and Preferences Regarding Urban Agriculture}

\author{
A-Young Lee ${ }^{1}$, Seon-Ok Kim ${ }^{2}$, and Sin-Ae Park ${ }^{1,3}$
}

Additional INDEX words. allotment garden, childhood education, gardening, horticultural activity, school garden, socio-horticulture

SUMMARY. This study aimed to investigate elementary school students' needs and preferences regarding urban agriculture. In total, 1268 students in grades 4 to 6 at four elementary schools in Seoul, South Korea, participated in the study. A 21-item questionnaire was developed and distributed in each school by trained researchers for 3 weeks in Oct. 2017. More than $73.7 \%$ of the students reported having an awareness of and need for urban agriculture, and $86.8 \%(\mathrm{~N}=1048)$ indicated their participation intention. Students noted needing urban agriculture for scientific

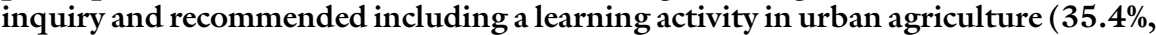
$\mathrm{N}=400)$ for psychological stability and stress reduction $(20.9 \%, N=236)$, and for leisure and hobby purposes $(16.2 \%, \mathrm{~N}=183)$. Students reported participating in urban agriculture activities in indoor and outdoor spaces $(33.8 \%, \mathrm{~N}=423)$ for more than 30 minutes and less than 60 minutes $(42.0 \%, \mathrm{~N}=525)$ twice per week $(40.2 \%$, $\mathbf{N}=501)$ with friends $(72.9 \%, N=818)$. Preferred urban agriculture indoor activities were planting plants $(21.8 \%, \mathrm{~N}=822)$, arranging flowers $(20.9 \%, \mathrm{~N}=$ 788 ), and making craftwork using plants $(18.9 \%, N=714)$. Harvesting $(20.8 \%, N=$ $790)$, watering $(15.1 \%, N=570)$, and planting transplants $(13.1 \%, N=493)$ were preferred outdoor activities. Other preferred activities included playing with livestock (22.4\%, $\mathrm{N}=884)$, cooking with the harvested crops $(21.3 \%, \mathrm{~N}=805)$, and feeding livestock $(17.2 \%, N=650)$. The female students demonstrated greater perception, experience, awareness of the necessity, and willingness to participate in urban agriculture compared with male students $(P=0.01)$. The lower the grade, the more students perceived the necessity of urban agriculture $(P<0.001)$. The results of this study can provide basic data for the practical development of urban agriculture programs for elementary school students.

I n South Korea, urban agriculture is defined as the cultivation of crops and ornamental plants, and the cultivation of insects and animals using various living spaces in urban areas (Korea Ministry of Government Legislation, 2017). In the United States, urban agriculture is defined as activities for producing, distributing, and marketing food and other agricultural and livestock products in the suburbs (Community Food Security Coalition, 2007). Furthermore, in the United States, urban agriculture is considered part of a large

This study was supported by the KU Research Professor Program of Konkuk University. This work was carried out with the support of the "Joint Research Project (Project title: Determining the Effects of Urban Agriculture Program for Health of Elementary School Students, Project No. PJ012808)," Rural Development Administration, Republic of Korea.

${ }^{1}$ Department of Environmental Health Science, Sanghuh College of Life Science, Konkuk University, Seoul 05029, South Korea

${ }^{2}$ Department of Animal and Plant Assisted Therapy, Graduate School of Agriculture and Animal Science, Konkuk University, Seoul 05029, South Korea

${ }^{3}$ Corresponding author. E-mail: sapark42@konkuk. ac.kr.

https://doi.org/10.21273/HORTTECH04150-18 community based on the food system continuum (Hodgson et al., 2011). The main scope of urban agriculture in South Korea involves activities such as hobbies, leisure, learning, or experience (Korea Ministry of Government Legislation, 2017). Thus, the definition differs according to the functions of urban agriculture in different countries (Hamilton et al., 2013; Hodgson et al., 2011; Mok et al., 2014).

Urban agriculture can be divided into the following four categories: 1 ) social aspects, such as community activity, social interaction, and secure community organization; 2) economic benefits, such as creating local jobs, using underused resources, and increasing household income; 3) health aspects, such as promoting public health by securing safe food, improving eating habits, and encouraging physical activity; and 4) reducing stormwater runoff and air pollution (carbon emissions), and promoting urban biodiversity and species in environmental aspects, such as increased conservation (Brown and
Carter, 2003; Hodgson et al., 2011; Kaufman and Bailkey, 2000; Lovell, 2010; Mallach, 2006; Teig et al., 2009; Veenhuizen, 2006). Public interest and participation in urban agriculture is rapidly increasing annually in South Korea (Huh et al., 2016). In 2010 , there were 150,000 domestic urban agriculture participants and 104 ha (257.0 acres) of urban gardens. By 2014, these figures had increased to 1.08 million and 668 ha (1650.7 acres), respectively. These activities mainly involve weekend farms, box house gardens, and urban agriculture for leisure or education (Jang et al., 2010; Kim et al., 2014; Park, 2016). In addition, various national policies have been enacted, such as the Act on the Promotion and Support of Urban Agriculture (no. 14650), and national qualifications for urban agriculture managers have been introduced (Korea Ministry of Government Legislation, 2017).

It is important to teach elementary school students about life concepts such as plants and animals to shift from animistic thinking that does not distinguish between living things and inanimate objects (Leddon et al., 2009; Piaget, 1929). To develop appropriate cognitive development during childhood, inquiries into life and the natural environment in elementary school curricula and experiential education are important (Ministry of Education, 2015). In this regard, the characteristics of urban agriculture that children experience in life directly, such as plants and animals, are consistent with their development and education. Moreover, urban agriculture acknowledges the importance of agriculture, which is the basis of life, and can be an effective educational tool for children. As such, children can realize the necessity and importance of urban agriculture (Fritz and Moody, 1997; Trexler and Suvedi, 1998).

Children are likely to be affected by urban agriculture in the following ways: 1) public health, such as increased physical activity, decreased childhood obesity through increased vegetable and fruit consumption, and the enhancement of nutritional status (Lovell, 2010; Ozer, 2007; Robinson-O'Brien et al., 2009; Williams and Dixon, 2013); 2) the development of new social relations, 
such as the formation of new neighborhood relations and enhanced family resilience in the community (Hodgson et al., 2011); and 3 ) behavioral modification aspects, such as improved eating habits (Hodgson et al., 2011). Moreover, Park et al. (2016) found that interventions centered on horticultural activities, which are the major activities of urban agriculture, can improve children's physical and physiologic aspects [e.g., cortisol (Lee et al., 2018), health status, and dietary habits (McAleese and Rankin, 2007)], psychological and emotional aspects [e.g., emotional intelligence (Jeon and Lee, 2015; Kim et al., 2007)], cognitive aspects [e.g., creativity (Lee and Kwack, 2010) and attention (Lee et al., 2013)], social aspects [e.g., peer relationships (Jung et al., 2009) and social skills (Jeon and Lee, 2015)], and educational aspects [e.g., academic achievement in science and math (Klemmer et al., 2005; Pigg et al., 2006)]. In countries such as South Korea, the United States, the United Kingdom, and Japan, urban agricultural programs tend to be similar to urban farming activities at school farms using educational garden spaces (Federation of City Farms and Community Gardens, 2016; Jang et al., 2016; Rural
Development Administration, 2018; U.S. Department of Agriculture, 2016).

Therefore, this study aimed to understand children's needs and preferences regarding urban agricultural activities to develop urban agricultural programs for them. Moreover, we compared and analyzed differences in children's preferences and demand for urban agriculture activities according to gender and grade.

\section{Materials and methods}

Subjects. A convenience sampling method was used to select the sample for this study. For recruitment, a letter was sent to 602 elementary schools in Seoul, South Korea, of which 52 responded that they would like to participate. Considering the distribution of autonomous regions in Seoul's 25 districts, four elementary schools were selected randomly in Nowon-gu, Seocho-gu, Jongno-gu, and Yongsan-gu. Among the 1632 elementary school students in grades 4 to 6 in the four schools, 1268 agreed to participate in the study and completed the consent form with parental consent.

Conducting Questionnaires. The elementary school students completed the questionnaires in Oct.
2017. Two trained researchers visited each class once in the four schools. The average number of students per class was about 25 , and the researchers explained the purpose of the questionnaire to them. Students were given $20 \mathrm{~min}$ to fill out the questionnaires, which were completed simultaneously. After the questionnaire was completed, a $\$ 5$ incentive was provided to every participant. The Bioethics Committee of Konkuk University approved this study (7001355-201709-HR199).

QUESTIONNAIRE CONSTRUCTION. A questionnaire comprising 21 items was constructed. The items covered the following aspects: urban agriculture experience and awareness (two items); urban agriculture interest, necessity, and participation intention (three items); urban agriculture participation type (five items); urban agriculture activity and plant preference (nine items); and demographic information (two items) (Tables 1-5).

At the beginning of the questionnaire, the definition of urban agriculture was explained. After reading the definition, the students answered the two questions about urban agriculture experience and awareness. If the students responded positively, an

Table 1. Awareness of and needs for urban agriculture according to children's gender, based on a study of elementary school children's needs and preferences for urban agriculture.

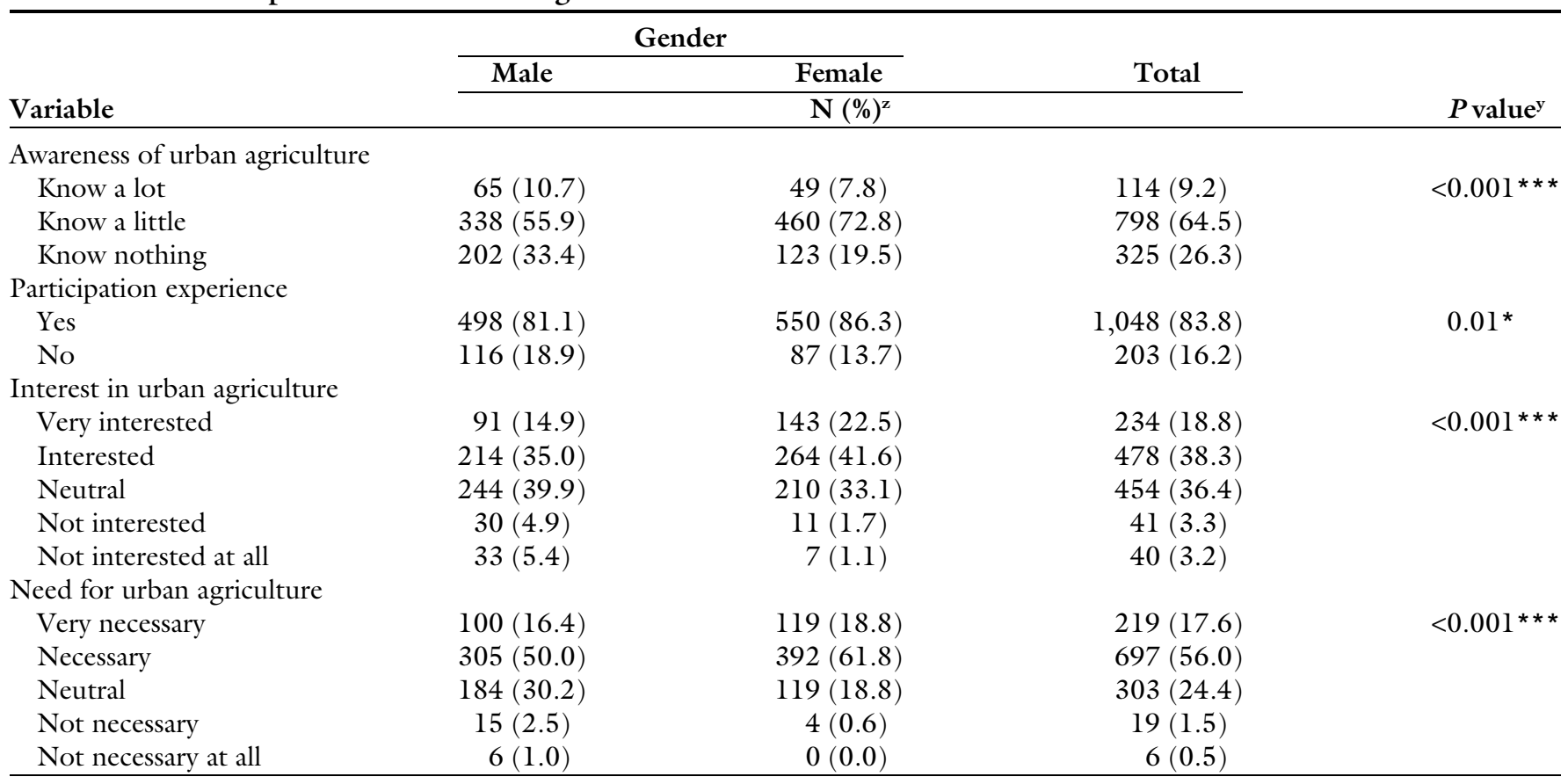

${ }^{\mathrm{z}} \mathrm{N}=1258$ (616 and 642 for male and female students, respectively).

${ }^{y}$ Chi-square test was performed to compare responses to items among gender groups, where $P<0.05$ was considered statistically significant

${ }^{*},{ }^{* *}$ Significant at $P<0.05$ or 0.001 , respectively. 
Table 2. Participative decisions and preferred participation types for urban agriculture programs in school according to children's gender, based on a study of elementary school students' needs and preferences for urban agriculture.

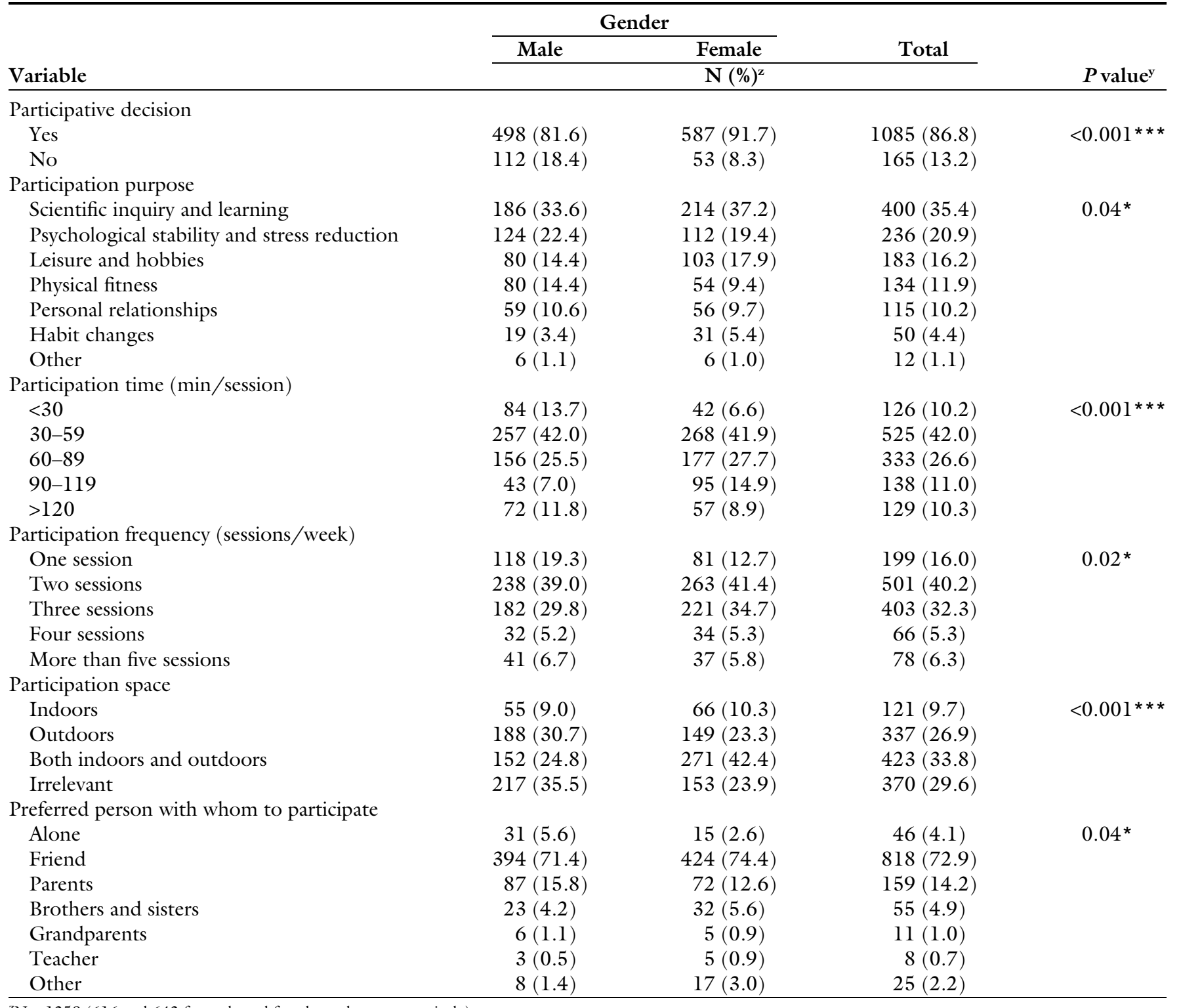

${ }^{\mathrm{z}_{\mathrm{N}}}=1258$ (616 and 642 for male and female students, respectively).

${ }^{\mathrm{y}}$ Chi-square test was performed to compare responses to items among gender groups, where $P<0.05$ considered statistically significant.

*, *** Significant at $P<0.05$ or 0.001 , respectively.

additional question linked to the answer asked about the source from which they had learned about urban agriculture. The students selected the appropriate answer from multiple choices. Furthermore, when students answered that they had experienced urban agriculture, they were asked to describe the types in which they had participated. Those who confirmed the necessity of urban agriculture were asked to choose multiple options regarding the reasons they participated therein.

The items were mostly closed questions, considering the reading level of students in different grades.
Moreover, the response options were numbered using Arabic numerals. Furthermore, we included photographs and a brief explanation of urban agriculture activities so that students could indicate in which they wanted to participate and their plant preferences. For example, the students were provided with photographs and brief explanations of 14 outdoor gardening activities (e.g., digging, mulching, watering, planting, weeding), and then checked three activities in which they wanted to participate. Moreover, photographs of 24 vegetables [e.g., lettuce (Lactuca sativa), spinach (Spinacia oleracea), carrot
(Dancus carota), potato (Solanum tuberosum)] were provided, from which the students selected the five they wanted to plant in a garden plot.

The questions in the questionnaire were based on previous studies (Hwang et al., 2010; Jeong et al., 2015; Lee and Cho, 2016; Pyo, 2001). The selection criteria for urban agriculture activities and plants for the preference questions were based on the Rural Development Administration (2017) and the plants listed in primary school textbooks (Chun, 2014; Kim, 2007).

The final questionnaire was developed based on a pilot test involving 
Table 3. Preferences for plants used in urban agriculture activities according to children's gender, based on a study of elementary school students' needs and preferences for urban agriculture.

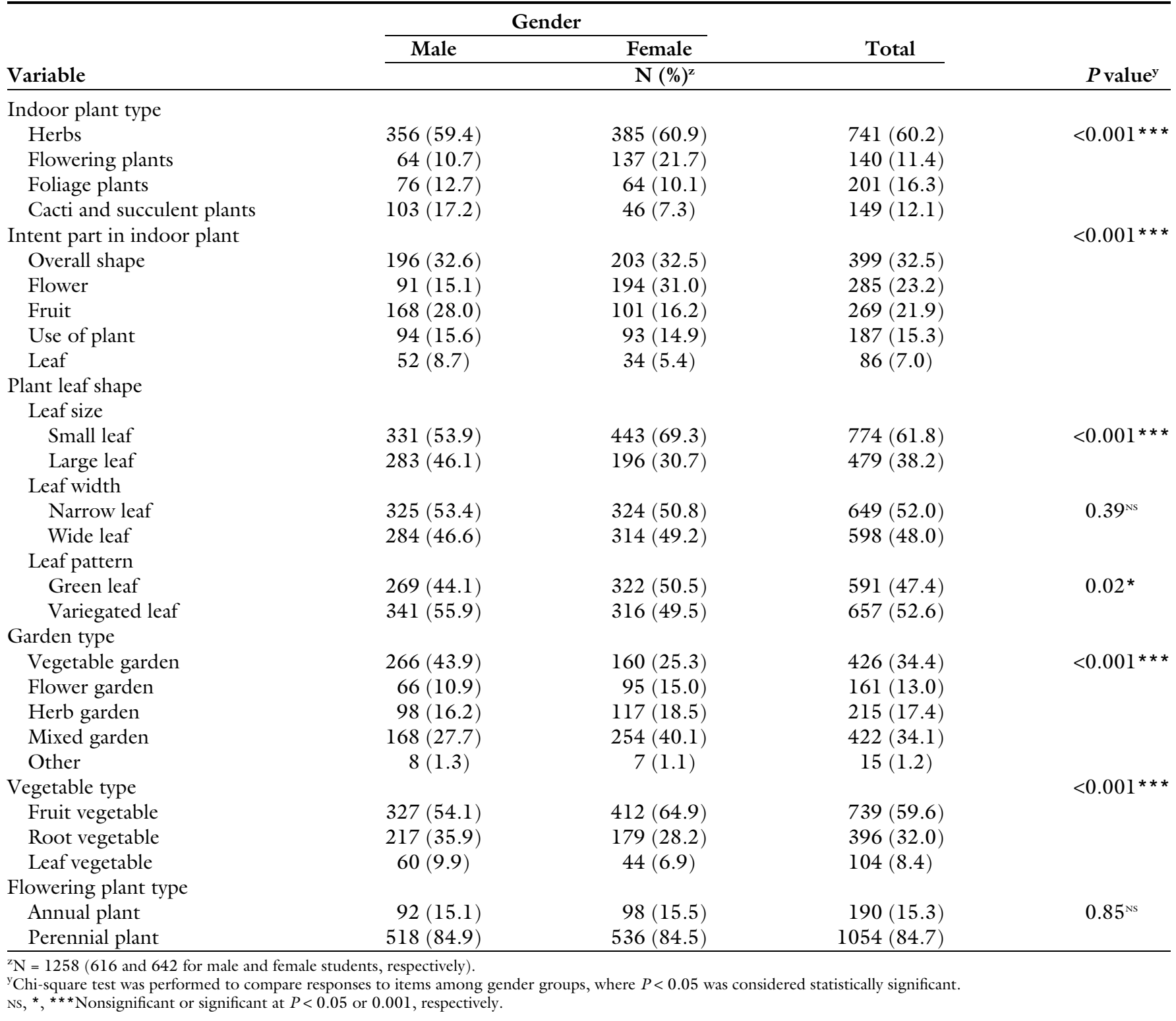

20 elementary school students. We considered the children's understanding of the questionnaire, estimation of the responses, questionnaire time, and the cost of the questionnaire.

Data anAlysis. SPSS (version 22.0; IBM Corp., Armonk, NY) was used to analyze the collected questionnaire data. Descriptive statistical analysis of the frequency and percentage was conducted for the demographic information and question data. There were missing data points in some of the categories in the survey results. Those data were dropped from the sample populations for calculating statistics. To compare elementary school students' demands and preferences regarding urban agriculture activities by gender and grade, a chi-square test was performed, with $P<0.05$ indicating statistical significance. Among the items related to urban agriculture and plant preference, multiple-response questions were excluded from the analysis of gender and grade differences in the statistical methodology.

\section{Results and discussion}

DEMOGRAPHIC INFORMATION. In total, 1268 students (616 boys, 642 girls, and 10 students who did not indicate their gender) with an average age of $11.9 \pm 0.8$ years completed the questionnaire. Of these, 479 students
$(37.8 \%)$ were in grade 4,413 students $(32.6 \%)$ were in grade 5 , and 376 students $(29.7 \%)$ were in grade 6 .

Awareness and eXPerience OF URBAN AGRICULTURE. Regarding awareness of urban agriculture, the elementary school students responded that they "know a lot" $(9.2 \%, \mathrm{~N}=114)$, "know a little" $(64.5 \%, \mathrm{~N}=798)$, and "know nothing" $(26.3 \%, \mathrm{~N}=325)$. Awareness of urban agriculture was high among the students (Table 1), but differed significantly according to gender $(P<0.001)$. Girls were more likely report awareness of urban agriculture $(14.0 \%, \mathrm{~N}=106)$ compared with boys.

Among the students who knew about urban agriculture $(\mathrm{N}=920)$, 
Table 4. Children's preferences for vegetables used in outdoor urban agriculture, based on a study of elementary school students' needs and preferences for urban agriculture (multiple responses).

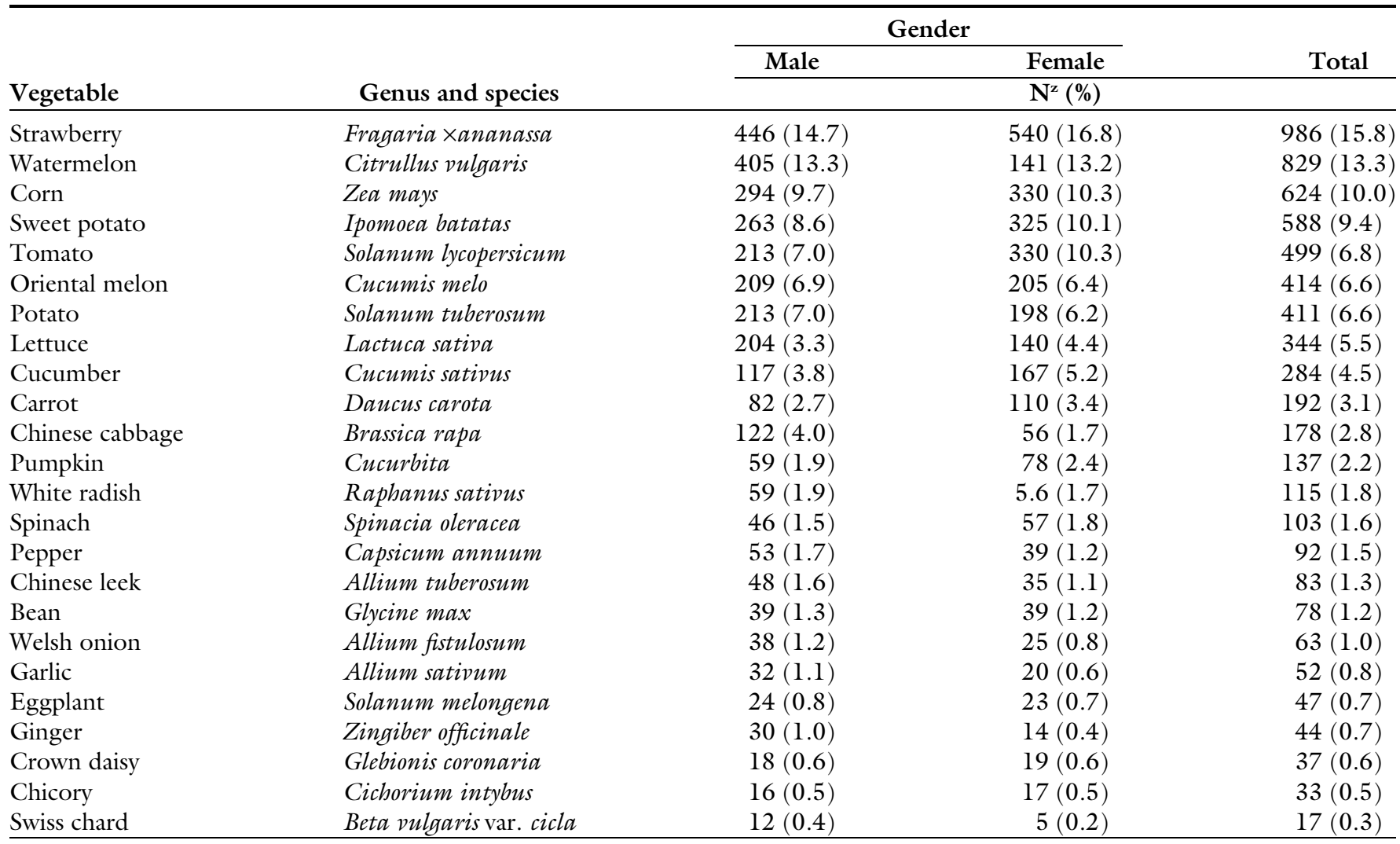

${ }^{\mathrm{z}} \mathrm{N}=1258$ (616 and 642 for male and female students, respectively).

$55.4 \%(\mathrm{~N}=516)$ reported that they learned about it through mass media such as television and the Internet, as well as the school curriculum such as science and in practical arts (Fig. 1).

Regarding experience with urban agriculture, $83.8 \%$ of the students $(\mathrm{N}=1048)$ reported they had participated in urban agriculture activities. Experience with urban agriculture was relatively high, and girls had more experience compared with boys $(P=$ 0.01 ; Table 1). The type of urban agriculture they experienced was mostly school gardening.

Regarding an interest in urban agriculture, students responded that they were "very interested" (18.8\%, $\mathrm{N}=234)$, "interested" $(38.3 \%, \mathrm{~N}=$ $478)$, "neutral" $(36.4 \%, \mathrm{~N}=454)$, "not interested" $(3.3 \%, \mathrm{~N}=41)$, and "not interested at all" $(3.2 \%, \mathrm{~N}=40)$ (Table 1). Interest in urban agriculture differed significantly by gender and grade $(P<0.001$; Table 1$)$. Interest in urban agriculture was $14.2 \%$ $(\mathrm{N}=102)$ greater among girls than boys, and greater in grade $4(62.7 \%$, $\mathrm{N}=294)$ than in grade $5(59.6 \%, \mathrm{~N}=$ $245)$ and in grade $6(47.6 \%, \mathrm{~N}=$ 179).
The elementary school students regarded urban agriculture as "very necessary" ( $17.6 \%, \mathrm{~N}=219)$, "necessary" $(56.0 \%, \mathrm{~N}=697)$, "neutral" $(24.4 \%, \mathrm{~N}=303)$, "not necessary" $(1.5 \%, \mathrm{~N}=19)$, and "not necessary at all" $(0.5 \%, \mathrm{~N}=6)$ (Table 1$)$, and there were significant differences by gender and grade $(P<0.001$; Table 1$)$. Girls considered it more important than boys by $14.2 \%(\mathrm{~N}=106)$. The need for urban agriculture was greatest for students in the lower grades as follows: grade $4,78.8 \%(\mathrm{~N}=372)$; grade $5,75.8 \%(\mathrm{~N}=311)$; and grade 6 , $64.4 \%(\mathrm{~N}=239)$.

Regarding the need, participants who responded that "we need urban agriculture" (73.6\%, $\mathrm{N}=916)$ reported it was "rewarding to raise animals and plants" $(22.5 \%, \mathrm{~N}=728)$ and that it promotes "scientific inquiry and learning" $(17.6 \%, \mathrm{~N}=$ $570)$, "mental and physical health" $(14.1 \%, \mathrm{~N}=457)$, and "leisure and hobbies" (11.6\%, $\mathrm{N}=374$ ) (Fig. 2).

The results from the questionnaire regarding students' awareness and experience of urban agriculture indicated that $73.7 \% \quad(\mathrm{~N}=912)$ "know about it" and 73.6\% ( $\mathrm{N}=$
916) "recognize its necessity" (Table 1). Thus, the degree of students' awareness of the concept of and need for urban agriculture was relatively high. In addition, a large proportion $(83.8 \%, \mathrm{~N}=1048)$ had experience with urban agriculture (Table 1). More than half the students were interested in urban agriculture activities. Girls understood better the concept of and need for urban agriculture, and had more experience and interest in it compared with boys $(P<0.05$; Table 1$)$. In Finland, a similar survey of students age 9 years and 10 years $(\mathrm{N}=76)$ found that female students had a greater intention to participate and more interest in cultivating plants than male students (Laaksoharju and Rappe, 2010). Those findings are consistent with the results of the current study regarding gender differences in relation to the need for urban agriculture.

In a previous study (Lee, 2009) in South Korea, less than half the Koreans living in cities in 2009 ( $\mathrm{N}=$ 90) were aware of urban agriculture (42.2\% "know about it" and $57.8 \%$ "know nothing"). Judging from the results of this study, awareness of 
Table 5. Children's preferences for flowering plants used in outdoor urban agriculture, based on a study of elementary school students' needs and preferences for urban agriculture (multiple responses).

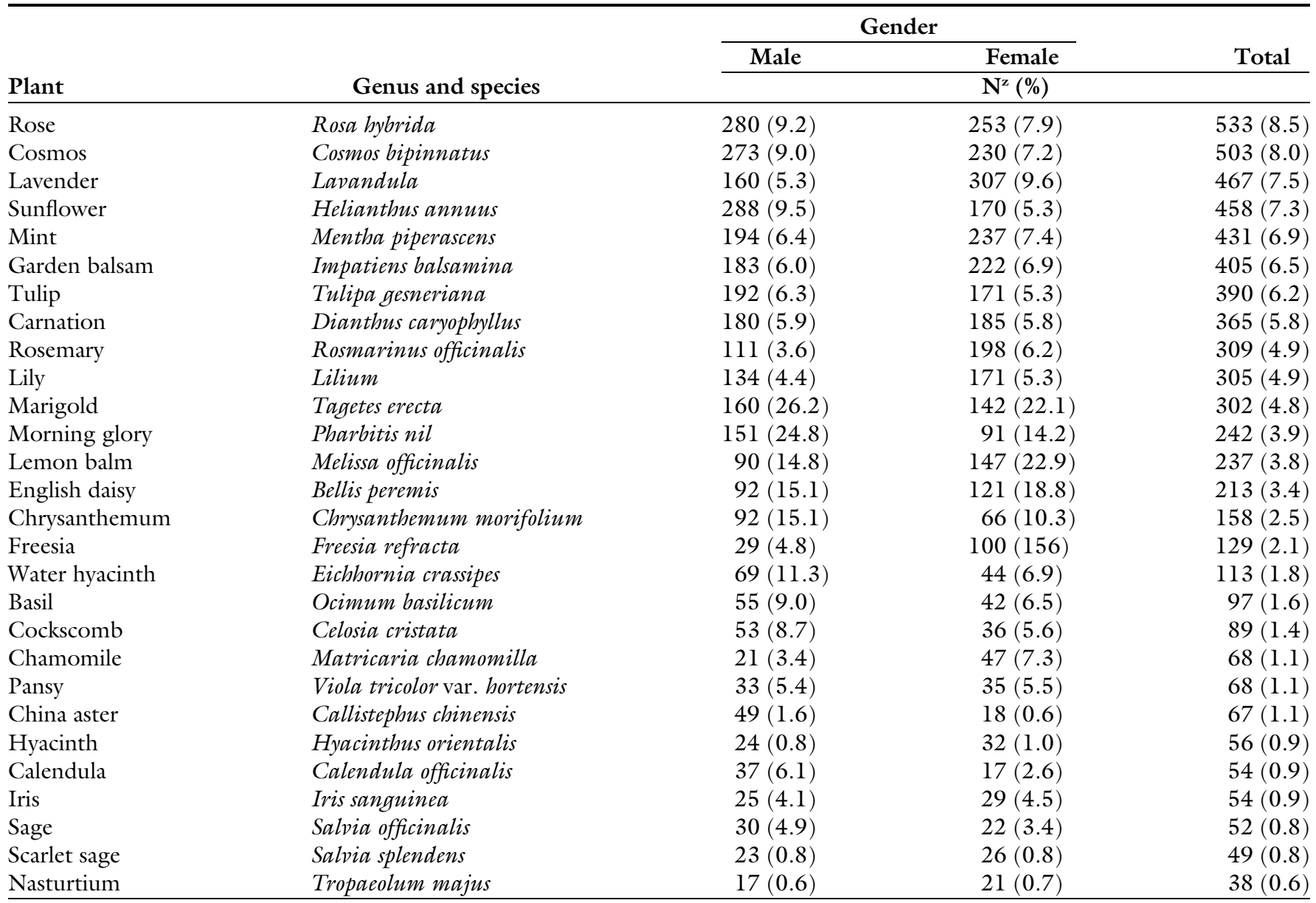

${ }^{\mathrm{z}} \mathrm{N}=1258$ (616 and 642 for male and female students, respectively).

urban agriculture in Korea has improved during the past 9 years $(73.7 \%$ of children in 2017). This improvement can be attributed to several recent achievements in urban agriculture. These include 1) maintenance by the system and establishment thereof (e.g., enactment of relevant laws and the introduction of a certification system for professionals in the field); 2) the expansion of infrastructure (e.g., expansion of spaces for activities, support for participation); 3 ) enhancement of education, extension, and public relations (e.g., initiation of an anniversary celebration); and 4) organization of urban agriculture events (e.g., holding farmers' markets, encouraging local foods) (Korea Agency of Education, Promotion and Information Service in Food, Agriculture, Forestry and Fisheries, 2015). These factors seem to have increased the public's awareness of urban agriculture.

Moreover, a recent study of Korean elementary, middle, and high school students found that $94.1 \%$ of female students and $78.1 \%$ of male students had experience with urban agriculture (Pee, 2017). However, $44.9 \%$ of the respondents responded negatively in terms of participation in urban agriculture activities. The reasons for the negative responses included the difficulty of performing labor-intensive outdoor urban agriculture activities, preferences for activities other than raising pets or plants, or a lack of time (Pee, 2017). As such, it is important to prepare appropriate urban agriculture activities that do not overwhelm children physically. In addition, to achieve urban agriculture strategies, children must be encouraged to raise pets or plants.

NEEDS AND TYPE OF PARTICIPATION IN URBAN AGRICULTURE IN SCHOOL. Of the students, $86.8 \%(\mathrm{~N}=1085)$ indicated a willingness to participate in urban agriculture programs at their schools, showing their positive views regarding introducing such programs (Table 2). The genders differed significantly in their willingness to participate in urban agriculture programs in schools $(P<0.001)$. The results indicated that $81.6 \%(\mathrm{~N}=498)$ of male and $91.7 \%(\mathrm{~N}=587)$ of female students wanted to participate in these programs-highlighting that female students had greater intention to participate.

Reasons to participate in urban agriculture programs were as follows: "scientific inquiries and learning" (35.4\%, $\mathrm{N}=400)$, "psychological stability and stress reduction" $(20.9 \%, \mathrm{~N}=236)$, and "leisure and hobbies" (16.2\%, $\mathrm{N}=183$ ) (Table 2). In addition to these common reasons from both genders, male students anticipated improving their "physical fitness" (14.4\%, $\mathrm{N}=80)$, whereas female students anticipated improving their "personal relationships" $(9.7 \%, \mathrm{~N}=56)$ by participating in urban agriculture programs $(P=$ 0.04; Table 2). 




Fig. 1. Means [\% (N)] by which students learned about urban agriculture, based on a 21 -item questionnaire developed to study the needs and preferences for urban agriculture among elementary school students (multiple responses).

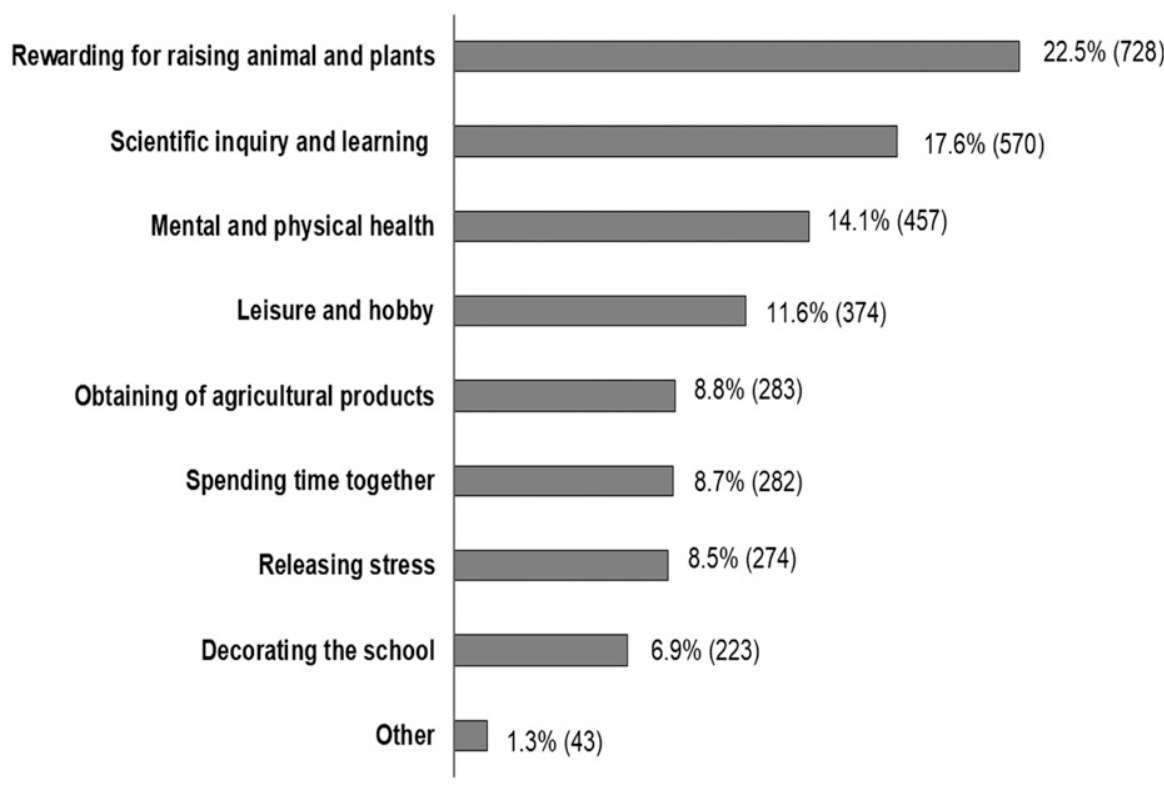

Fig. 2. Reasons [\% (N)] urban agriculture is needed according to children, based on a 21 -item questionnaire developed to study the needs and preferences for urban agriculture among elementary school students.

Several previous studies highlighted the potential benefits of urban agriculture activities, such as improving scientific knowledge and research
Krasny, 2003; Graham et al., 2005; O'Brien and Shoemaker, 2006; Wells et al., 2015). For example, in New York, Washington, Alaska, and Iowa, elementary school students $(\mathrm{N}=$ 3061) participated in a weekly urban agriculture program for 2 years. The results showed that participants' scientific knowledge of botany and nutrition improved significantly compared with that of the control group (Wells et al., 2015). For elementary school students $(\mathrm{N}=1326)$ in grade 3 in Texas, children with more urban agriculture experience had greater exposure to and preference for vegetables, consuming more of them compared with children with less urban agriculture experience (Evans et al., 2016).

Regarding children's preferences for certain types of urban agriculture programs at school (i.e., frequency, time, space, companions), respondents generally indicated a willingness to participate in them with friends for 30 to 59 min twice per week at indoor and outdoor places (Table 2). There were significant differences by gender and grade on these trends $(P<0.05)$. Male students preferred to participate in an urban agriculture activity for a shorter time with less frequency, whereas female students preferred a longer time with greater frequency. Children in the lower grades preferred to participate in urban agriculture activities more frequently, whereas those in the higher grades preferred to do so less frequently (Table 2). Regarding where the respondents wanted to engage in urban agricultural activities, male students did not care about the place, but female students wanted to participate in both indoor and outdoor spaces $(P<0.001$; Table 2$)$. Likewise, grade 4 students did not care about the place, whereas students in grades $\mathbf{5}$ and 6 said they wanted to participate in both indoor and outdoor spaces $(P<0.001)$. Students in the higher grades wanted to participate in urban agriculture with their friends, whereas those in the lower grades wanted to participate in urban agriculture with their families $(P<0.001$; Table 2$)$. Finally, the majority of respondents were interested in nature inquiry and learning $(35.4 \%, \mathrm{~N}=400)$ by participating in regular and continuous programmed urban agriculture activities for 30 to $59 \min (41.9 \%, \mathrm{~N}=525)$ in capacity, encouraging better diets, promoting physical activities, and improving communication and selfeffacement (Blair, 2009; Doyle and 
both indoor and outdoor spaces $(33.8 \%, \mathrm{~N}=423)$ twice per week $(40.2 \%, \mathrm{~N}=501)$ with their friends $(72.9 \%, \mathrm{~N}=818)$.

Studies on children's participation in urban agriculture found that their activities mainly involved school gardening (Kim et al., 2014; Pee, 2017). Moreover, these consisted of individual, intermittent urban agriculture activities such as special activity time and club activities instead of regular class time. In addition, most participated in urban agriculture activities once per week $(34.8 \%), 1$ to $2 \mathrm{~h}(63.4 \%)$ per session. The children surveyed in this study differed in terms of their preferred forms of urban agriculture participation. Urban agricultural activities at school are operated individually and intermittently, because the degrees of interest and support among school administrators and teachers determine their sustainability. Problems include a lack of activity management, time, expertise, and educational curricula (Ahn et al., 2011; Fido and Gayford, 1982; Kim et al., 2014; McKenzie et al., 1986; Pee, 2017).

In California, elementary school administrators (1706 schools) engaged in urban agricultural activities conducted a survey on the status of urban agriculture. The results showed that $89 \%$ of elementary schools used urban agriculture for academic instruction, $86 \%$ for science, $64 \%$ for environmental education, $63 \%$ for nutrition education, $58 \%$ for mathematics, and $35 \%$ for agricultural education (Graham et al., 2005). Previous studies, as well as ours, found similar trends in children's desire to participate in urban agriculture activities for natural inquiry and learning (Graham et al., 2005). According to the California School Garden Network (2014), which surveyed the current state of urban agricultural activities in California, children age 8 to 10 years were operating within regular school hours $(87.8 \%)$, which is different from the situation in South Korea.

Urban agricultural activities were mainly carried out by teachers $(53.4 \%)$, volunteers $(29.2 \%)$, other staff members $(21.8 \%)$, and horticultural experts (11.8\%). Furthermore, $51.5 \%$ of the students said they did not have related education support (California School Garden Network,
2014). In the United States, the major difficulties in urban agricultural management included a lack of time for teachers' urban agriculture activities $(88 \%)$, difficulty linking these activities in the curricula (74\%), and a lack of educational knowledge and interest (70\%) (Graham et al., 2005).

The most effective method for achieving the nature inquiry and learning effect - the main aspects of children's urban agriculture activities surveyed in this study - is to conduct regular urban agriculture activities in outdoor spaces (e.g., vacant lots, gardens, forests, rooftops) at school, where it is easy for teachers to access the children, as well as in indoor spaces. It is important that these activities be conducted by teachers trained professionally in urban agriculture (Martin, 2003; Slade et al., 2013). To effectively manage urban agricultural activities on campus, it is necessary to continuously intervene with input from trained urban agricultural professionals.

Preferred uRban agriculture ACtivities. To investigate students' preferred urban agriculture activities, we classified the activities as follows: 1) indoor urban agricultural activities, 2 ) outdoor urban agricultural activities, and 3 ) other urban agricultural activities. For indoor urban agriculture, $21.8 \%(\mathrm{~N}=822)$ of the students said that the activity they most wanted to experience was "planting plants," $20.9 \%(\mathrm{~N}=788)$ said "flower arrangement," and $18.9 \%(\mathrm{~N}=714)$ indicated making craftwork using plants (Fig. 3). Preferred outdoor urban agriculture activities were harvesting $(20.8 \%, \mathrm{~N}=790)$, watering $(15.1 \%, \mathrm{~N}=570)$, planting transplants $(13.1 \%, \mathrm{~N}=493)$, and sowing seeds (9.4\%, $\mathrm{N}=353$ ) (Fig. 4). Regarding other urban agriculture activities, $22.4 \%(\mathrm{~N}=884)$ of the students said they would like to experience playing with livestock; $21.3 \%(\mathrm{~N}=$ 805), cooking with harvested crops; and $17.2 \%(\mathrm{~N}=650)$, feeding the livestock (Fig. 5).

The most favored indoor plants were "herbs" $(60.2 \%, \mathrm{~N}=741)$, "foliage plants" $(16.3 \%, \mathrm{~N}=201)$, "cactus and succulent plants" (12.1\%, $\mathrm{N}=149$ ), and "flowering plants" $(11.4 \%, \mathrm{~N}=140)$ (Table 3). There were statistically significant differences in indoor plant preference by gender $(P<0.001)$. For indoor plants, male students preferred herbs $(59.4 \%, \mathrm{~N}=356)$, cactus and succulent plants $(17.2 \%, \mathrm{~N}=103)$, and foliage plants $(12.7 \%, \mathrm{~N}=76)$. $\mathrm{Fe}$ male students preferred herbs $(60.9 \%$, $\mathrm{N}=385$ ), flowering plants $(21.7 \%, \mathrm{~N}=$ $137)$, and foliage plants $(10.1 \%, \mathrm{~N}=$ 64). Male students tended to prefer cacti and succulent plants, and female students, flowering plants.

The most common interests among the elementary school students were "the overall shape of the plant" $(32.5 \%, \mathrm{~N}=399)$, "flower" $(23.2 \%, \mathrm{~N}=285)$, "fruit" ( $21.9 \%, \mathrm{~N}=$ $269)$, and "use of plant" ( $15.3 \%, \mathrm{~N}=$ 187) (Table 3). Again, there were statistically significant differences according to gender $(P<0.001)$. Male students were interested in the overall shape of the plant $(32.6 \%, \mathrm{~N}=$ $196)$, fruit $(28.0 \%, \mathrm{~N}=168)$, and use of the plant $(15.6 \%, \mathrm{~N}=94)$. Female students were interested in the overall shape of the plant $(32.5 \%, \mathrm{~N}=203)$, flower $(31.0 \%, \mathrm{~N}=194)$, and fruit $(16.2 \%, \mathrm{~N}=101)$. Although both boys and girls were most interested in the overall shape of the plant, boys were more interested in fruit; girls were more interested in flowers.

Regarding the shape of the plant leaf, students preferred smaller leaf sizes $(61.8 \%, \mathrm{~N}=774)$ over larger ones $(38.2 \%, \mathrm{~N}=479)$. In total, $52.0 \%(\mathrm{~N}=649)$ of the respondents preferred narrow leaves and $48.0 \%$ $(\mathrm{N}=598)$ preferred wide leaves. For leaf pattern, $47.4 \%(\mathrm{~N}=591)$ of the students preferred a pattern, whereas $52.6 \%(\mathrm{~N}=657)$ did not. Furthermore, there were statistically significant differences according to students' gender and grade. Boys preferred leaves with patterns $(55.9 \%, \mathrm{~N}=$ 341) whereas girls preferred no pattern $(50.5 \%, \mathrm{~N}=322)$. By grade, $60.2 \%$ of grade $4(\mathrm{~N}=283)$ preferred leaves with patterns whereas those in grade $5(50.9 \%, \mathrm{~N}=209)$ and in grade $6(52.7 \%, \mathrm{~N}=197)$ preferred no pattern $(P=0.05)$.

These gender differences in plant preferences seem to be attributed to the focus of female students on the beauty and joy of plants, whereas male students focus more on practical factors (Laaksoharju and Rappe, 2010). In addition, it has been reported that school-age children focus on the usefulness of plants and that plantuse preferences differ by gender and age (Hammann, 2011; Krüger and 




Fig. 3. Preferences [\% (N)] for indoor urban agriculture activities among children, based on a 21 -item questionnaire developed to study the needs and preferences for urban agriculture among elementary school students (multiple responses).

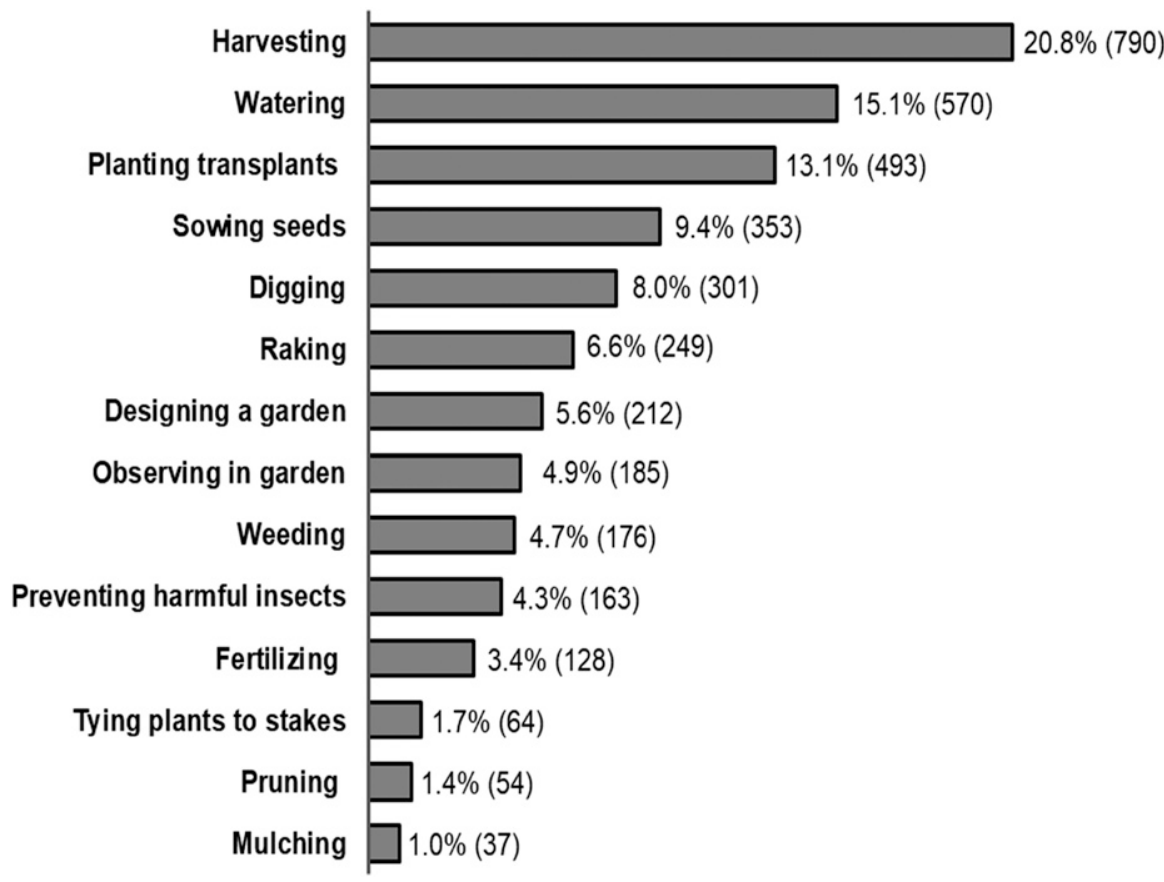

Fig. 4. Preferences $[\%(\mathrm{~N})]$ for outdoor urban agriculture activities among children, based on a 21 -item questionnaire to study the needs and preferences for urban agriculture among elementary school students (multiple responses).

Burmester, 2005). Pany and Heidinger (2015) reported that more than $65 \%$ of Australian students age 10 to 19 years $(\mathrm{N}=1299)$ indicated medicinal plants as their favorite plants. Similarly, the current study identified herbs as the most preferred plants.
$(34.1 \%, \mathrm{~N}=422)$, "herb gardens" $(17.4 \%, \mathrm{~N}=215)$, "flower gardens" $(13.0 \%, \mathrm{~N}=161)$, and others (1.2\%, $\mathrm{N}=15$ ). Most boys said they wanted to create a "vegetable garden" $(43.9 \%, \mathrm{~N}=266)$ whereas girls wanted a "mixed garden" (40.1\%, $\mathrm{N}=254, P<0.001$; Table 3 ). Most of grade 6 students said they wanted to create a "vegetable garden" $(40.2 \%, \mathrm{~N}=150)$, whereas those from grades $4(37.1 \%, \mathrm{~N}=176)$ and $5(38.2 \%, \mathrm{~N}=152)$ wanted a "mixed garden" $(P<0.001)$.

The most preferred vegetable types for gardening were "fruit vegetables" $(59.6 \%, \mathrm{~N}=739)$, "root vegetables" $(32.0 \%, \mathrm{~N}=396)$, and "leaf vegetables" $(8.4 \%, \mathrm{~N}=104)$ (Table $3)$. The vegetable crops they wanted to grow directly were "strawberry (Fragaria $\times$ ananassa)" $(15.8 \%, \mathrm{~N}=$ 986), "watermelon (Citrullus vulgaris)" $(13.3 \%, \mathrm{~N}=829)$, "corn $($ Zea mays)" (10.0\%, $\mathrm{N}=624)$, and "sweetpotato (Ipomoea batatas)" $(9.4 \%, \mathrm{~N}=588)$ (Table 4). Regarding flowering plants, "perennial plants" $(84.7 \%, \mathrm{~N}=1054)$ were preferred to "annual plants" $(15.3 \%, \mathrm{~N}=190)$ (Table 3). In the case of flowering plants, students wanted to grow "rose (Rosa bybrida)" (8.5\%, $\mathrm{N}=533)$, "cosmos (Cosmos bipinnatus)" $(8.0 \%, \mathrm{~N}=503)$, "lavender (Lavandula sp.)" (7.5\%, $\mathrm{N}=467)$, and "sunflower (Helianthus annums)" $(7.3 \%, \mathrm{~N}=458)$ (Table 5).

Regarding the plant preferences of 590 elementary school students, the preferred edible crops were corn $(31.2 \%)$, sweetpotato $(29.0 \%)$, and potato $(24.2 \%)$. In the case of leafstem vegetables, lettuce $(33.6 \%)$, spinach $(22.7 \%)$, and chinese cabbage (Brassica campestris, 18.3\%) were the most common, with watermelon $(35.4 \%)$, strawberry $(29.8 \%)$, and melon (Cucumis melo), followed by carrot $(36.6 \%)$, radish (Raphanus sativus, 23.9\%), and lotus root (Nelumbonucifera, 15.4\%). Moreover, for flowers, 1-year-old cosmos (34.2\%), garden balsam (Impatiens balsamina, $21.0 \%$ ), and sunflower $(13.6 \%)$ were preferred, whereas the most preferred perennials were daisy (Bellis perennis, 34.2\%) carnation (Dianthus caryophyllus, 30.0\%), and chrysanthemum (Chrysanthemum morifolium, 20.0\%) (Pуо, 2001). Similar trends in previous studies on plant preferences can be attributed to 


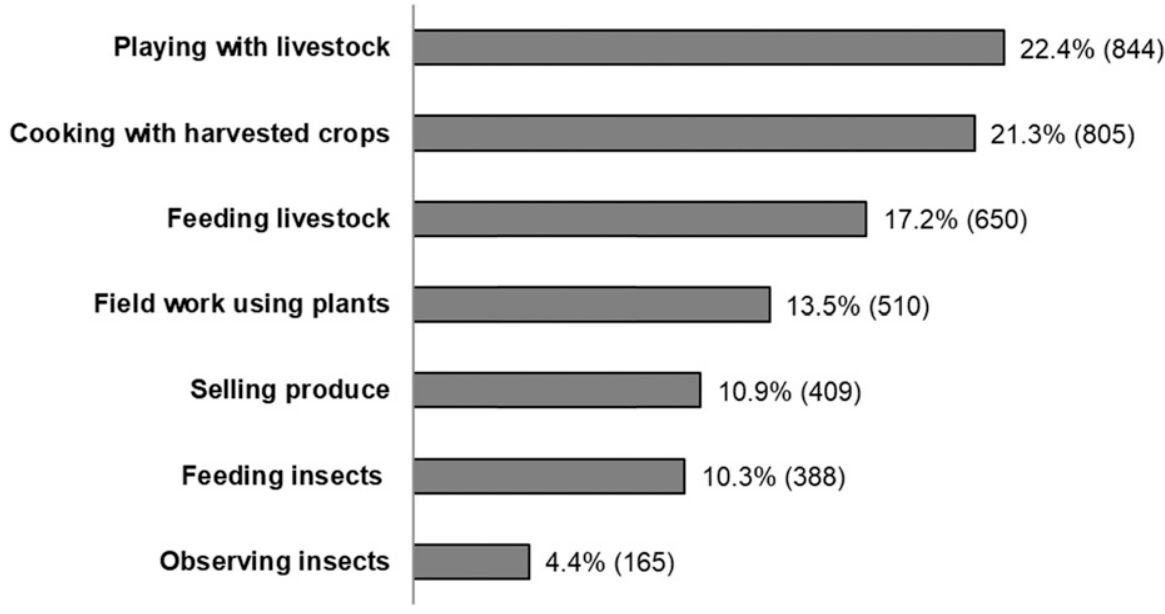

Fig. 5. Preferences [\% (N)] for other urban agriculture activities among children, based on a 21 -item questionnaire developed to study the needs and preferences for urban agriculture among elementary school students (multiple responses).

frequent exposure to certain plants, which is the factor with the greatest effect on plant preference (Harrison, 1977; Jeong et al., 2000; Lim, 2002; Seo et al., 2015).

The most preferred indoor urban agriculture activities among students were planting plants $(21.8 \%, \mathrm{~N}=$ $822)$, arranging flowers $(20.9 \%, \mathrm{~N}=$ 788 ), and making craftwork using plants (18.9\%, $\mathrm{N}=617$ ) (Fig. 3). For other urban agricultural activities, harvesting $(20.9 \%, \mathrm{~N}=790)$, watering $(15.1 \%, \mathrm{~N}=570)$, and planting transplants $(13.1 \%, \mathrm{~N}=493)$ were preferred (Fig. 4). Additional preferred urban agriculture activities were playing with livestock $(22.4 \%$, $\mathrm{N}=844)$, cooking with harvested crops $(21.3 \%, \mathrm{~N}=805)$, and feeding the livestock $(17.2 \%, \mathrm{~N}=650)$ (Fig. $5)$. According to Pee (2017), the preferred outdoor urban agriculture activities of Korean students in grades 4 to 6 (212 students) were planting transplants $(24.8 \%)$, watering (18.6\%), and harvesting (16.5\%), similar to the findings of the current study.

Moreover, urban agriculture programs that students wanted to experience included making food using processed foods $(47.1 \%$ male, $58.0 \%$ female), making processed food using the harvested crops (18.2\% male, $14.5 \%$ female), and making compost tea $(17.1 \%$ male, $15.3 \%$ female). These results are also similar to those of previous studies that indicate a relatively high preference for culinary activities using crops, among other urban agricultural activities (Pee, 2017). We think that the students in our study preferred activities such as harvesting because they believed it reinforced their activities and efforts positively. In terms of child development, the reinforcement of the harvest effectively enhances the motivation and self-efficacy to participate in urban agriculture activities (Morin, 2017).

In the United States, Denver Urban Gardens (2012) reported that $80 \%$ of urban farming activities in Denver, CO, were activities for children, and $90 \%$ of urban farmers participated in urban agriculture activities, including friends, family, and people in need. Of these, $60 \%$ contributed to food assistance programs (Denver Urban Gardens, 2012). As such, harvesting through urban agriculture by children is an important element that increases educational effectiveness and produces social benefits for schools and communities.

Meanwhile, among 100 experts who provided education on animals and plants in zoos in the United States, children were asked about the relationship between animals and plants $(94 \%)$, understanding of life $(93 \%)$, and nature protection $(93 \%)$. Here, $87 \%$ of the experts had experience running an animal-plant joint education program, not only an animal-based education program. This reflects the recognition of plant-based education by education experts. It was reported that $46 \%$ of the programs were divided into plant education activities and animal education activities, 14\% were animal education activities including plant education, and $24 \%$ combined both programs (Conley, 2009). Accordingly, education activities with animals and gardening activities together should be properly introduced, considering children's high preferences for activities such as playing with domestic animals. In a survey regarding improvements to urban agriculture activities for children in Korea, $71.6 \%$ of the respondents answered that the diversification of cultivated crops is needed most. In addition, the improvement of activity facilities (20.5\%), and diversity in education and training programs $(5.7 \%)$ had the greatest number of responses (Kim et al., 2014).

In conclusion, the results of this study are as follows. First, elementary school students' perceptions of and participation in urban agriculture activities were relatively high. We confirmed their high level of awareness of the need for urban agriculture activities and high need to participate in urban agricultural programs. We also identified the children's preferred types of urban agriculture participation (e.g., activity purpose, frequency, time, and space), and preferred urban agricultural activities and plant types. Furthermore, we confirmed that preferences tend to differ by gender. In developing urban agricultural programs for children, we developed various types of urban agriculture content and activities that use the plants preferred by elementary school students. Most of the children wanted rather short-term urban agriculture activities of more than $30 \mathrm{~min}$ and less than $60 \mathrm{~min}$. These findings can be used to increase the effectiveness and participation satisfaction of urban agriculture activities for children through regular and continuous activities.

However, the elementary school students in this study cannot represent all Korea elementary school students. This study focused on elementary school students in Seoul, the capital city of South Korea. Future studies should investigate elementary school students in other cities in South Korea. In addition, further research should examine the effects of urban agricultural childcare programs developed based on the results of this study. Finally, surveys on urban agriculture activities in various 
subjects should be conducted on those in various age groups or with different social status-for example, the elderly or people with disabilities.

\section{Literature cited}

Ahn, J.J., S.S. Jo, K.H. Lee, S.S. Kim, E.J. Jang, J.W. Hong, and C.H. Park. 2011. A study on the models corresponding to elementary school garden types. Hort. Sci. Technol. 29(Suppl. II):192 .

Blair, D. 2009. The child in the garden: An evaluative review of the benefits of school gardening. J. Environ. Educ. 40:15-38.

Brown, K.H. and A. Carter. 2003. Urban agriculture and community food security in the United States: Farming from the city center to the urban fringe. 10 Nov. 2017 . <www.foodsecurity.org/ PrimerCFSCUAC.pdf>.

California School Garden Network. 2014. The 2014 California school garden survey. 17 Nov. 2017. <http://www. csgn.org/blog/2013/12/12/take2014-california-school-garden-survey>.

Chun, M.P. 2014. Research on plants in elementary school textbook and plants in elementary schools. Daegu Haany University, PhD Diss.

Community Food Security Coalition. 2007. The North American urban and peri-urban agriculture alliance. 15 Nov. 2017 . <www. foodsecurity.org/ NAUPAA_description_Nov_2007.pdf $>$.

Conley, J. 2009. In the zoological garden: Understanding botany in zoo education. University of Delaware, PhD Diss.

Denver Urban Gardens. 2012. Growing community gardens. 11 Nov. 2017. <https://dug.org/wp-content/ uploads $/ 2015 / 02 /$ Best-Practices.pdf $>$.

Doyle, R. and M. Krasny. 2003. Participatory rural appraisal as an approach to environmental education in urban community gardens. Environ. Educ. Res. 9:91-115.

Evans, A., N. Ranjit, C.N. Fair, R. Jennings, and J.L. Warren. 2016. Previous gardening experience and gardening enjoyment is related to vegetable preferences and consumption among low-income elementary school children. J. Nutr. Educ. Behav. 48:618-624.

Federation of City Farms and Community Gardens. 2016. Federation of city farms and community gardens. 15 Nov. 2017. <https://www.farmgarden.org.uk/>.
Fido, H. and C. Gayford. 1982. Field work and the biology teacher: A survey in secondary schools in England and Wales. J. Biol. Educ. 16:27-34.

Fritz, S. and L. Moody. 1997. Assessment of junior high/middle school agricultural education programs in Nebraska. J. Agr. Educ. 38(1):61-65.

Graham, H., D.L. Beall, M. Lussier, P. McLaughlin, and S. Zidenberg-Cherr. 2005. Use of school gardens in academic instruction. J. Nutr. Educ. Behav. 37:147-151.

Hamilton, A.J., K. Burry, H.F. Mok, F. Barker, J.R. Grove, and V.G. Williamson. 2013. Give peas a chance? Urban agriculture in developing countries: A review. Agron. Sustain. Dev. 34(1):45-73.

Hammann, M. 2011. Wie groß ist das Interesse von Schülern an Heilpflanzen? Z. Phytother. 32:15-19.

Harrison, A.A. 1977. Mere exposure, p. 610-646. In: L. Berkowitz (ed.). Advances in experimental social psychology. Academic Press, New York, NY.

Hodgson, K., M.C. Campbell, and M. Bailkey. 2011. Investing in healthy, sustainable places through urban agriculture. Funders' Network Smart Growth Livable Communities, Coral Gables, FL.

Huh, J.N., M.H. Park, and J.E. Im. 2016. Promotion strategy of urban agriculture. Korea Rural Economic Institute, Naju, Korea.

Hwang, J.I., Y.J. Choi, B.G. Jang, and S.A. Rhee. 2010. Segmentation and characteristic analysis of urban farmers behavior. Korean Soc. Community Living Sci. 21:619-631.

Jang, Y.A., S.J. Jung, E.H. Yoo, K.M. Gim, J.H. Moon, and D.K. Park. 2016. What a school garden! Rural Development Administration, Jeonju, Korea.

Jang, J.H., E.O. Kim, and J.E. Jo. 2010. A study on the current situation of urban agriculture program and activating plan: Focused on Anyang city. Community Dev. Rev. 35(2):61-70.

Jeon, H.K. and C.S. Lee. 2015. The effect of a horticultural activity program on emotional intelligence, social ability and social adaptability of children in singleparent families. Indian J. Sci. Technol. 8:299-305.

Jeong, J.S., S.Z. Kwon, and T.D. Cho. 2000. A study on the preference factor of pot aromatic herbs. J. People Plants Environ. 3:69-83.

Jeong, S.H., S.M. Lee, G.M. Gim, H.J. Lim, and H. Park. 2015. Analysis of hor- ticultural preference for elementary violence prevention program development of horticulture. Hort. Sci. Technol. 33(Suppl. II):238.

Jung, M.S., J.H. Lee, and Y.O. Jeong. 2009. The effects of a group horticulture activity of herb plant on the improvement of peer relations and class cohesion in the lower grades. J. Korean Practical Arts Educ. 22:107-124.

Kaufman, J. and M. Bailkey. 2000. Farming inside cities: Entrepreneurial urban agriculture in the United States. 17 Nov. 2017. <www.lincolninst.edu/ pubs/dl/95_KaufmanBaikey00.pdf>.

Kim, J.H. 2007. Content analysis of plants education in practical arts textbook of elementary school. J. Agr. Educ. Human Resource Dev. 39(3):23-43.

Kim, T.G., J.N. Heo, and J.H. Jeon. 2014. Expansion of healing function of urban agriculture and ways for urban and rural cooperation. Korea Rural Economic Inst., Naju, Korea.

Kim, S.K., J.S. Lee, J.N. Jeon, and M.H. Chiang. 2007. The effect of a psychological-horticultural therapy program for promoting emotional intelligence. J. People Plant Environ. 10:135-141.

Klemmer, C.D., T.M. Waliczek, and J.M. Zajicek. 2005. Growing minds: The effect of a school gardening program on the science achievement of elementary students. HortTechnology 15:448452 .

Korea Agency of Education Promotion and Information Service in Food, Agriculture, Forestry and Fisheries. 2015. Design a city with agriculture. 15 Nov. 2017. <http://www.okdab.com/news/ issueTrend/issueView.do? issueSeq $=881$ \& searchValue $=$ \& currentPage $=1>$.

Korea Ministry of Government Legislation. 2017. Laws on development and support of urban agriculture. 15 Nov. 2017. <http://www.law.go.kr/lsInfoP.do? 1 siSeq $=192490 \&$ efYd=20170922\#0000>.

Krüger, D. and A. Burmester. 2005. Wie Schüler Pflanzen ordnen. Z. Didakt. Natwiss. 11:85-102.

Laaksoharju, T. and E. Rappe. 2010. Children's relationship to plants among primary school children in Finland: Comparisons by location and gender. HortTechnology 20:689-695.

Leddon, E.M., S.R. Waxman, and D.L. Medin. 2009. Unmasking "alive": Children's appreciation of a concept linking all living things. J. Cogn. Dev. 9:461-473.

Lee, J.H. 2009. A study on the current status and realization of urban agriculture 
in Korea. Daesan Agricultural Foundation, Seoul, Korea.

Lee, D.G. and S.H. Cho. 2016. Analysis on the preference of urban agriculture types in accordance with lifestyle. J. Korean Inst. Landscape Architecture 44:40-50.

Lee, M.J., J. Kim, W. Oh, and J.S. Jang. 2013. Effects of indoor horticultural activities on improvement of attention and concentration in elementary school students. Weonye Gwahag Gisulji 31:821-827.

Lee, E.Y. and H.R. Kwack. 2010. Development of gardening program on the effect of increasing creativity based on "Sparks of Genius.". J. Korean Practical Arts Educ. 16:67-92.

Lee, M.J., W. Oh, J.S. Jang, and J.Y. Lee. 2018. A pilot study: Horticulture-related activities significantly reduce stress levels and salivary cortisol concentration of maladjusted elementary school children. Complement. Ther. Med. 37:172-177.

Lim, M.S. 2002. Flower preference study of young adults in their twenties. J. Korea Floral Art Res. Assn. 4:92-142.

Lovell, S.T. 2010. Multifunctional urban agriculture for sustainable land use planning in the United States. Sustainability 2:2499-2522.

Mallach, A. 2006. Bringing buildings back: From abandoned properties to community assets: A guidebook for policymakers and practitioners. Rutgers University Press, Newark, NJ.

Martin, S.C. 2003. The influence of outdoor schoolyard experiences on students' environmental knowledge, attitudes, behaviors, and comfort levels. J. Elementary Sci. Educ. 15:51-63.

McAleese, J.D. and L.L. Rankin. 2007. Garden-based nutrition education affects fruit and vegetable consumption in sixthgrade adolescents. J. Amer. Dietetic Assn. 107:662-665.

McKenzie, G.D., R.O. Utgard, and M. Lisowski. 1986. The importance of field trips: A geological example. J. Coll. Sci. Teach. 9-10:17-20.

Ministry of Education. 2015. 2015 National curriculum revision. 11 Nov. 2017. <http://ncic.go.kr/mobile.revise. board.list.do?degreeCd=RVG01 \& board $\mathrm{No}=1003>$.

Mok, H.F., V.G. Williamson, J.R. Grove, K. Burry, S.F. Barker, and A.J. Hamilton. 2014. Strawberry fields forever? Urban agriculture in developed countries: A review. Agron. Sustain. Dev. 34:21-43.
Morin, D. 2017. The effects of inclusion and positive reinforcement within the classroom. 11 Nov. 2017. <http:// scholarworks.merrimack.edu/honors_ component $/ 4>$.

O'Brien, S.A. and C.A. Shoemaker. 2006. An after-school gardening club to promote fruit and vegetable consumption among fourth grade students: The assessment of social cognitive theory constructs. HortTechnology 16:24-29.

Ozer, E.J. 2007. The effects of school gardens on students and schools: Conceptualization and considerations for maximizing healthy development. Health Educ. Behav. 34:846-863.

Pany, P. 2014. Students' interest in useful plants: A potential key to counteract plant blindness. Plant Sci. Bull. 60:18-27.

Pany, P. and C. Heidinger. 2015. Uncovering patterns of interest in useful plants: Frequency analysis of individual students' interest types as a tool for planning botany teaching units. Multidisciplinary J. Educ. Social Technol. Sci. 2:15-39.

Park, D.K. 2016. Current status and strategies to encourage participation of urban agriculture enriching conventional agriculture. Res. Food Agr. Rural Policy. 56:253-274.

Park, S.A., A.Y. Lee, G.J. Lee, D.S. Kim, W.S. Kim, C.A. Shoemaker, and K.C. Son. 2016. Horticultural activity interventions and outcomes. Hort. Sci. Technol. 34:513-527.

Pee, O.J. 2017. Analysis of citizen vegetable garden and school farm activities in Sejong city. Chungbuk National University, PhD Diss.

Piaget, J. 1929. The child's conception of the world. Harcourt Brace, New York, NY.

Pigg, A.E., T.M. Waliczek, and J.M. Zajicek. 2006. Effects of a gardening program on the academic progress of third, fourth, and fifth grade math and science students. HortTechnology 16:262264.

Pyo, S.H. 2001. A study of elementary school students' preference level on plants in their textbooks. Korea National University of Education, MS Thesis.

Robinson-O'Brien, R., M. Story, and S. Heim. 2009. Impact of garden-based youth nutrition intervention programs: A review. J. Amer. Dietetic Assn. 109:273280.
Rural Development Administration. 2017. Urban agriculture. Rural Development Administration, Jeonju, Korea.

Rural Development Administration. 2018. School farm. 11 June 2018. <http://www.nongsaro.go.kr/portal/ ps / psz/psza/content Main.ps? menuId =PS00384\&cntntsNo=12814\& totalSearchYn $=\mathrm{Y}>$.

Seo, J.S., J.M. Kim, K.H. Song, and E.S. Je. 2015. A survey on preference for vegetables among higher grade students to develop gardening activity programs. J. People Plants Environ 2015(7):115.

Slade, M., C. Lowery, and K. Bland. 2013. Evaluating the impact of forest schools: A collaboration between a university and a primary school. Support Learn. 28:66-72.

Teig, E., J. Amulya, L. Bardwell, M. Buchenau, J.A. Marshall, and J.S. Litt. 2009. Collective efficacy in Denver, Colorado: Strengthening neighborhoods and health through community gardens. Health Place 15:1115-1122.

Trexler, C.J. and M. Suvedi. 1998. Perception of agriculture as a context for elementary science teaching: A case of change in Sanilac county, Michigan. J. Agr. Educ. 39(4):28-36.

U.S. Department of Agriculture. 2016. The farm to school census. 15 Nov. 2017. <https://farmtoschoolcensus.fns.usda. gov $/>$.

Veenhuizen, R.V. 2006. Cities farming for the future: Urban agriculture for green and productive cities. International Development Research Centre, Ottawa, ON, Canada.

Wells, N.M., B.M. Myers, L.E. Todd, K. Barale, B. Gaolach, G. Ferenz, M. Aitken, C.R. Henderson, C. Tse, K.O. Pattison, C. Taylor, L. Connerly, J.B. Carson, A.Z. Gensemer, N.K. Franz, and E. Falk. 2015. The effects of school gardens on children's science knowledge: A randomized controlled trial of low-income elementary schools. Intl. J. Sci. Educ. 37:28582878.

Williams, D.R. and P.S. Dixon. 2013. Impact of garden-based learning on academic outcomes in schools: Synthesis of research between 1990 and 2010. Rev. Educ. Res. 83:211-235. 